\title{
Relative Efficiency of Health Provision: a DEA Approach with Non-discretionary Inputs
}

\author{
António Afonso ${ }^{\# \$}$ and Miguel St. Aubyn ${ }^{\#}$
}

December 2006

\begin{abstract}
We estimate a semi-parametric model of health production process using a two-stage approach for OECD countries. By regressing data envelopment analysis output efficiency scores on non-discretionary variables, both using Tobit analysis and a single and double bootstrap procedure, we show that inefficiency is strongly related to GDP per head, the education level, and health behaviour such as obesity and smoking habits. The used bootstrapping procedure corrects likely biased DEA output scores taking into account that environmental variables are correlated to output and input variables.
\end{abstract}

JEL: C14, C61, H52, I11

Keywords: technical efficiency, health, DEA, bootstrap, semi-parametric

\footnotetext{
* The opinions expressed herein are those of the authors and do not necessarily reflect those of the author's employers.

${ }^{\#}$ UECE - Research Unit on Complexity and Economics; Department of Economics, ISEG/TULisbon Technical University of Lisbon, R. Miguel Lupi 20, 1249-078 Lisbon, Portugal, emails: aafonso@iseg.utl.pt, mstaubyn@iseg.utl.pt.

\$European Central Bank, Directorate General Economics, Kaiserstraße 29, D-60311 Frankfurt am Main, Germany, email: antonio.afonso@ecb.int.
} 


\section{Contents}

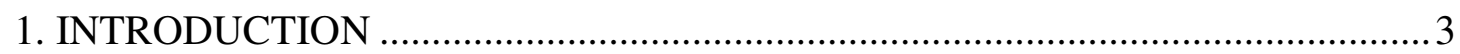

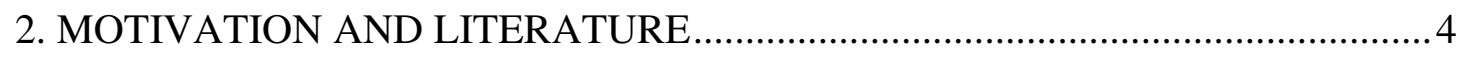

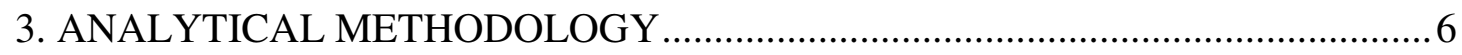

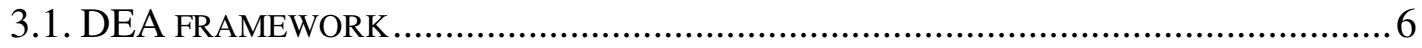

3.2. NON-DISCRETIONARY INPUTS AND THE DEA/TOBIT TWO-STEPS PROCEDURE....... 7

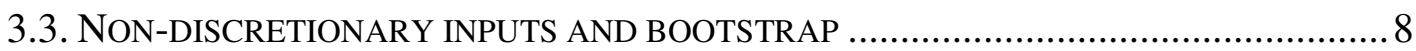

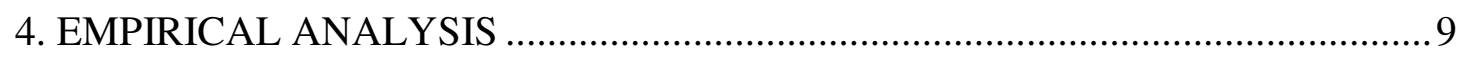

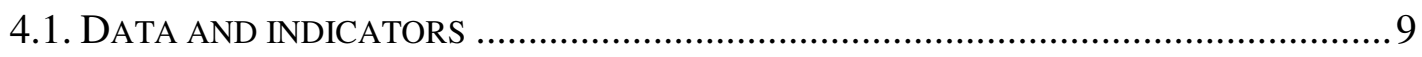

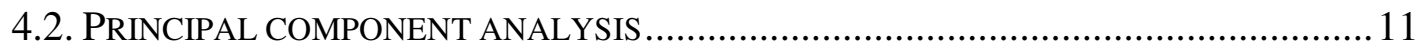

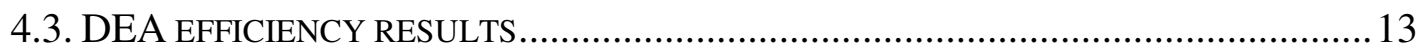

4.4. EXPLAINING INEFFICIENCY - THE ROLE OF NON-DISCRETIONARY INPUTS ........... 14

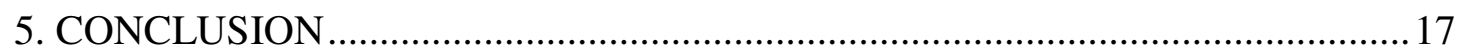

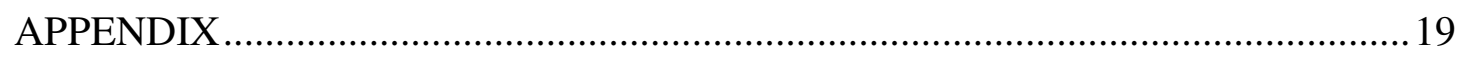

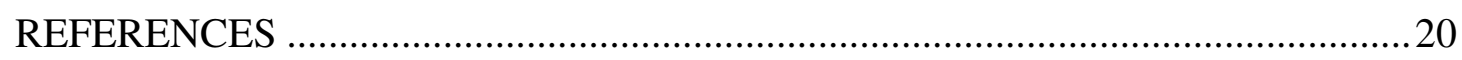

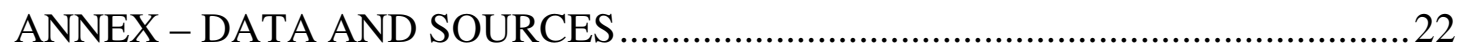

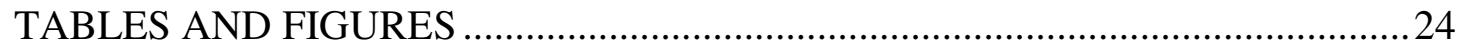




\section{Introduction}

In this paper we systematically compare the output from the health system of a set of OECD countries with resources employed (doctors, nurses, beds and diagnostic technology equipment). Using data envelopment analysis (DEA), we derive a theoretical production frontier for health. In the most favourable case, a country is operating on the frontier, and is considered as efficient. However, most countries are found to perform below the frontier and an estimate of the distance each country is from that borderline is provided - the so-called efficiency score. Moreover, estimating a semi-parametric model of the health production process using a two-stage approach, we show that inefficiency in the health sector is strongly related to variables that are, at least in the short- to medium run, beyond the control of governments. These are GDP per capita, the education level, and unhealthy lifestyles as obesity and smoking habits.

In methodological terms, a two-stage approach has become increasingly popular when DEA is used to assess efficiency of decision-making units (DMUs). The most usual two-stage approach has been recently criticised in statistical terms. ${ }^{1}$ The fact that DEA output scores are likely to be biased, and that the environmental variables are correlated to output and input variables, recommend the use of bootstrapping techniques, which are well suited for the type of modelling we apply here. Therefore, we employ both a more usual DEA/Tobit approach and single and double bootstrap procedures suggested by Simar and Wilson (2007). Our paper is one of the first application examples of this very recent technique. ${ }^{2}$ Our results following this procedure are compared to the ones arising from the more traditional one.

The paper is organised as follows. In section two we provide motivation and briefly review some of the literature and previous results on health provision efficiency. Section three outlines the methodological approach used in the paper and in section four we present and discuss the results of our efficiency analysis. Section five provides the conclusions.

\footnotetext{
${ }^{1}$ See Simar and Wilson $(2000,2007)$.

${ }^{2}$ See Afonso and St. Aubyn (2006) for an application to the education system.
} 


\section{Motivation and literature}

Health is one of the most important services provided by governments in almost every country. According to OECD (2005), OECD countries expended an average of 8.7 per cent of GDP in 2003 on health institutions, of which 6.3 per cent of GDP were from public sources. In a general sense, health provision is efficient if its producers make the best possible use of available inputs, and the sole fact that health inputs weight heavily on the public purse would call for a careful efficiency analysis. A health system not being efficient would mean either that results (or "outputs") could be increased without spending more, or else that expense could actually be reduced without affecting the outputs, provided that more efficiency is assured. Research results presented here indicate that there are cases where considerable improvements can be made in this respect.

The fact of health spending being predominantly public is particularly true notably in OECD countries. Table 1 summarises some relevant data for thirty OECD countries concerning health spending. For instance, public expenditure as a share of total spending averaged 72.5 per cent in 2003 , ranging from 44.4 per cent in the USA to 90.1 per cent in the Czech Republic. For the EU15, average total spending was 8.8 per cent of GDP in 2003, which is close to the OECD value, slightly up from the 8.1 per cent ratio observed in 1995. On the other hand, average public expenditure as a share of total expenditure in health was, in 2003, lower in the EU15 than in the OECD, the corresponding ratios being equal to 69.9 and 72.5 percent, respectively. Furthermore, data reported in Table 1 show that total per capita health spending is very diverse across OECD countries. Indeed, the country that spends more on health in per capita terms, the USA, expends more than two times the OECD average and eleven times more than the country that spends the least, Turkey, even though the per capita GDP ratio between those two countries is roughly five and a half.

[Insert Table 1 here] 
Moreover, the relevance of assessing the quality of public spending and redirecting it to more growth enhancing items is stressed, for instance, in EC (2004) as being an important goal for governments to pursue. Internationally, there is a shift in the focus of the analysis from the amount of public resources used by a government, to services delivered, and also to achieved outcomes and their quality (see OECD, 2003).

In our research, we measure and compare health output across countries using precisely the abovementioned type of quality measures - we resort to the most recent cross-nationally comparable evidence on health variables, as reported in OECD (2005).

Previous research on the international comparative performance of the public sector in general and of health outcomes in particular, including Afonso, Schuknecht and Tanzi (2005) for public expenditure in the OECD, and Gupta and Verhoeven (2001) for education and health in Africa, has already suggested that important inefficiencies are at work. These studies use free disposable hull analysis (FDH) with inputs measured in monetary terms. Spinks and Hollingsworth (2005) assess health efficiency for OECD countries using DEA based Malmquist indexes. They report a mean value of 0.961 for an OECD dataset suggesting that overall, member countries have moved slightly away from the frontier, implying a decrease in technical efficiency, between 1995 and 2000. Using both FDH and DEA analysis, Afonso and St. Aubyn (2005) studied efficiency in providing health and education in OECD countries using physically measured inputs and concluded that if all countries were efficient, input usage could be reduced by about 13 per cent without affecting output. Using a more extended sample Evans et al. (2000) evaluate the efficiency of health expenditure in 191 countries using a parametric methodology. In addition, Afonso and St. Aubyn (2006) also used a two-step approach for education performance in OECD countries.

In this paper, we estimate semi-parametric models of the health production process using a two-stage approach. In a first stage, we determine the output efficiency score for each country, using the mathematical programming approach known as DEA, relating health inputs to outputs. In a second stage, these scores are explained using regression analysis. Here, we show that non-discretionary factors are indeed highly correlated to inefficiency, i.e., they are significant "environmental variables", using 
DEA jargon. ${ }^{3}$ They are, however, of a fundamentally different nature from input variables, in so far as their values cannot be changed in a meaningful spell of time by the DMU, here a country.

\section{Analytical methodology}

\subsection{DEA framework}

DEA, which assumes the existence of a convex production frontier, allows the calculation of technical efficiency measures that can be either input or output oriented. The purpose of an output-oriented study is to evaluate by how much output quantities can be proportionally increased without changing the input quantities used. This is the perspective taken in this paper. Note, however, that one could also try to assess by how much input quantities can be reduced without varying the output. Both output and input-oriented models will identify the same set of efficient/inefficient producers or DMUs. ${ }^{4}$

The description of the linear programming problem to be solved, output oriented and assuming variable returns to scale hypothesis, is sketched below. Suppose there are $p$ inputs and $q$ outputs for $n$ DMUs. For the i-th DMU, $y_{i}$ is the column vector of the outputs and $x_{i}$ is the column vector of the inputs. We can also define $X$ as the $(p \times n)$ input matrix and $Y$ as the $(q \times n)$ output matrix. The DEA model is then specified with the following mathematical programming problem, for a given i-th DMU:

$$
\begin{array}{ll}
\operatorname{Max}_{\lambda, \delta_{i}} \delta_{i} \\
\text { s. to } & \delta_{i} y_{i} \leq Y \lambda \\
& x_{i} \geq X \lambda \\
& n 1^{\prime} \lambda=1 \\
& \lambda \geq 0
\end{array}
$$

3 Throughout the paper we use interchangeably the terms "non-discretionary", "exogenous" and "environmental" when qualifying variables or factors not initially considered in the DEA programme.

${ }^{4}$ See Farrell (1957) seminal work, popularised by Charnes, Cooper and Rhodes (1978). Coelli, Rao, O'Donnell and Battese (2005) and Thanassoulis (2001) offer good introductions to the DEA methodology. 
In problem (1), $\delta_{i}$ is a scalar satisfying $\delta_{i} \geq 1$, more specifically it is the efficiency score that measures technical efficiency of the i-th unit as the distance to the efficiency frontier, the latter being defined as a linear combination of best practice observations. With $\delta_{i}>1$, the decision unit is inside the frontier (i.e. it is inefficient), while $\delta_{i}=1$ implies that the decision unit is on the frontier (i.e. it is efficient). The vector $\lambda$ is a $(n \times 1)$ vector of constants that measures the weights used to compute the location of an inefficient DMU if it were to become efficient.

\subsection{Non-discretionary inputs and the DEA/Tobit two-steps procedure}

The standard DEA models as the one described in (1) incorporate only discretionary inputs, those whose quantities can be changed at the DMU will, and do not take into account the presence of environmental variables or factors, also known as nondiscretionary inputs. However, socio-economic differences may play a relevant role in determining heterogeneity across DMUs - either schools, hospitals or countries' achievements in an international comparison - and influence outcomes. In what health is concerned, these exogenous socio-economic factors can include, for instance, household wealth, eating habits and education level.

As non-discretionary and discretionary inputs jointly contribute to each DMU outputs, there are in the literature several proposals on how to deal with this issue, implying usually the use of two-stage and even three-stage models. ${ }^{5}$

Let $z_{i}$ be a $(1 \times r)$ vector of non-discretionary outputs. In a typical two-stage approach, the following regression is estimated:

$$
\hat{\delta}_{i}=z_{i} \beta+\varepsilon_{i}
$$

where $\hat{\delta}_{i}$ is the efficiency score that resulted from stage one, i.e. from solving (1). $\beta$ is a $(r \times 1)$ vector of parameters to be estimated in step two associated with each

\footnotetext{
${ }^{5}$ See Ruggiero (2004) and Simar and Wilson (2007) for an overview.
} 
considered non-discretionary input. The fact that $\hat{\delta}_{i} \geq 1$ has led many researchers to estimate (2) using censored regression techniques (Tobit), although others have used OLS. $^{6}$

Figure 1 illustrates the basic idea behind a two-stage approach. In a simplified one output and one input DEA problem, A, B and C are found to be efficient, while D is an inefficient DMU. The output score for unit D equals $\left(d_{1}+d_{2}\right) / d_{1}$, and is higher than one. However, unit D inefficiency may be partly ascribed to a "harsh environment" a number of perturbing environmental factors may imply that unit $\mathrm{D}$ produces less than the theoretical maximum, even if discretionary inputs are efficiently used. In our example, and if the environment for unit D was more favourable (e. g. similar to the sample average), then we would have observed $D_{c}$. In other words, unit $\mathrm{D}$ would have produced more and would be nearer the production possibility. The environment corrected output score would be $\left(d_{1 c}+d_{2 c}\right) / d_{1 c}$, lower than $\left(d_{1}+d_{2}\right) / d_{1}$, and closer to unity.

[Insert Figure 1 here]

\subsection{Non-discretionary inputs and bootstrap}

The two-stage DEA/Tobit method is likely to be biased in small samples for two reasons. Firstly, the fact that output scores are jointly estimated by DEA implies that the error term $\varepsilon_{i}$ in equation (2) is serially correlated. Secondly, non-discretionary variables $z_{i}$ are correlated to the error term $\varepsilon_{I}$. This derives from the fact that nondiscretionary inputs are correlated to the outputs, and therefore to estimated efficiency scores.

To surmount this, Simar and Wilson (2007) propose two alternatives based on bootstrap methods ${ }^{7}$. Similarly to the DEA/Tobit procedure, the efficiency score

\footnotetext{
${ }^{6}$ See Simar and Wilson (2007) for an extensive list of published examples of the two step approach.

${ }^{7}$ See also Afonso and St. Aubyn (2006) for an application to education efficiency in OECD countries, where the method is exposed in more detail.
} 
depends linearly on the environmental variables, but the error term is a truncated, and not censored, normal random variable ${ }^{8}$.

The first bootstrap method ("algorithm 1") implies the estimation of the efficiency scores using DEA, as in the DEA/Tobit analysis. However, the influence of nondiscretionary inputs on efficiency is estimated by means of a truncated linear regression. Coefficient significance is then assessed by bootstrapping. We have considered 2000 bootstrap estimates for that effect.

The scores derived from DEA are biased towards 1 in small samples. Simar and Wilson (2007) second bootstrap procedure, "algorithm 2", includes a parametric bootstrap in the first stage problem, so that bias-corrected estimates for the efficiency scores are produced. These corrected scores replace the DEA original ones, and estimation of environment effects proceeds like in algorithm 1.

\section{Empirical analysis}

\subsection{Data and indicators}

OECD (2005) is our chosen health database for OECD countries. ${ }^{9}$ Typical input variables include medical technology indicators and health employment. Output is to be measured by indicators such as life expectancy and infant mortality, in order to assess potential years of added life.

It is of course difficult to measure something as complex as the health status of a population. We have not innovated here, and took two usual measures of health attainment, infant mortality and life expectancy. ${ }^{10}$

\footnotetext{
${ }^{8}$ We implemented these algorithms in Matlab. Programmes and functions are available on request.

${ }^{9}$ The data and the sources used in the paper are presented in the Annex.

${ }^{10}$ These health measures, or similar ones, have been used in other studies on health and public expenditure efficiency - see Afonso, Schuknecht and Tanzi (2004), and Gupta and Verhoeven (2001).
} 
Efficiency measurement techniques used in this paper imply that outputs are measured in such a way that "more is better." This is clearly not the case with infant mortality. Recall that the Infant Mortality Rate (IMR) is equal to:

(Number of children who died before 12 months)/(Number of born children) $\times 1000$.

We have calculated an "Infant Survival Rate", ISR,

$$
I S R=\frac{1000-I M R}{I M R}
$$

which has two nice properties: it is directly interpretable as the ratio of children that survived the first year to the number of children that died; and, of course, it increases with a better health status.

We have considered a third output measure, which we call Potential Years of Life Not Lost, PYLNL. This variable was computed on the basis of the indicator Potential Years of Life Lost, PYLL, reported by OECD (2005). This last variable, PYLL, equals the number of life years lost due to all causes before the age of 70 and that could be, $a$ priori, prevented. Therefore, and for our subsequent DEA analysis, and similarly to the Infant Mortality Rate, a transformation had to be done, in order to provide an increasing monotonic relation between the variable, number of years not lost, and health status.

Our transformed variable is:

$$
P Y N L L=\lambda-P Y L L
$$

where $\lambda=3618010$ is an estimate of the number of potential years of life for a population under 70 years. ${ }^{11}$

\footnotetext{
${ }^{11}$ See details in the Appendix.
} 
Therefore, our frontier model for health is based upon three output variables:

- the infant survival rate,

- and life expectancy,

- potential years of life not lost.

We compare physically measured inputs to outcomes. Quantitative inputs are the number of practising physicians, practising nurses, acute care beds per thousand habitants and high-tech diagnostic medical equipment, specifically magnetic resonance imagers (MRI). ${ }^{12}$ Table 2 reports the relevant statistics for the set of OECD countries.

[Insert Table 2 here]

From Table 2 one notices that practising nurses per one thousand persons, in the period 2000-2003, ranged from 1.6 in Korea to 14.7 in Ireland. For the same period there was also a high range of practising physicians per one thousand persons, from 1.4-1.5 in Turkey and in Korea to 4.3-4.4 in Italy and in Greece. Additionally, the number of MRI per million persons ranged from 0.2 in Mexico to 32.2 in Japan, and the hospital acute care beds per one thousand persons ranged from 1.0 in Mexico to 9.1 in Japan.

Table 2 also shows that for the period 2000-2003 life expectancy at birth ranged form 68.4 years in Turkey to 81.5 in Japan, and infant mortality ranged form 2.4 in Iceland to 36.3 in Turkey. In addition, the potential years of life not lost per 100000 population was 73 per cent above the average in Hungary and 29 per cent below average in Japan.

\subsection{Principal component analysis}

In order to go around the eventual difficulties posed to the DEA approach when there are a significant number of inputs and/or outputs, we used principal component analysis (PCA) to aggregate some of the indicators. The use of PCA reduces the

\footnotetext{
${ }^{12}$ A commonly used indicator of medical technology; see, for instance, Retzlaff-Roberts et al. (2004).
} 
dimensionality of multivariate data, which is what we have regarding health status, and the health care resources used.

The idea of PCA is to describe the variation of a multivariate data set through linear combinations of the original variables (see, for instance, Everitt and Dunn, 2001). Generally, we are interested in seeing if the first few components portray most of the variation of the original data set, for instance, 80 per cent or 90 per cent, without much loss of information. In a nutshell, the principal components are uncorrelated linear combinations of the original variables, which are then ranked by their variances in descending order. This provides a more parsimonious representation of the data set and avoids that in the DEA computations too many DMUs are labelled efficient by default.

Usually one applies PCA by imposing that the original variables are normalized to have zero mean. This means that the computed principal components scores also have zero mean, and therefore some of the results from PCA are negative. Since DEA inputs and outputs need to be strictly positive, PCA results will be increased by the most negative value in absolute value plus one, in order to ensure strictly positive data (see, for instance, Adler and Golany, 2001).

We applied PCA to the four input variables, doctors, nurses, beds and MRI units. The results of such analysis (see Table 3) led us to use the first three principal components as the three input measures, which explain around 88 per cent of the variation of the four variables. This also implies that we only take into account the components whose associated eigenvalues are above 0.7 , a rule suggested by Jollife (1972).

Applying PCA also to the set of our selected output variables, life expectancy, infant survival rate and potential number of years of life not lost, we selected the first principal component as the output measure since it accounts for around 84 per cent of the variation of the three variables (see Table 3).

[Insert Table 3 here] 
We report in Table 4 the abovementioned principal components, to be used in the subsequent section in DEA computations.

\section{[Insert Table 4 here]}

\subsection{DEA efficiency results}

In Table 5 we report results for the standard DEA variable-returns-to-scale technical efficiency output scores and peers of each of the considered countries. The specification used includes as inputs the first three components of the PCA performed to the base variables doctors, nurses, beds and MRI units. As output we use the first component of the PCA applied to the base variables infant survival rate, life expectancy, and potential years of life not lost, as explained in the previous section.

\section{[Insert Table 5 here]}

It is possible to observe in Table 5 that seven countries would be located on the theoretical production possibility frontier with the standard DEA approach: Canada, Finland, Japan, Korea, Spain, Sweden and the USA ${ }^{13}$. Canada, Finland, Japan, Spain and Sweden are located in the efficient frontier because they perform quite well in the output indicator, getting above average results. On the other hand, Korea and the USA are generally below average regarding the use of resources in all the first three components selected. Another set of three countries is located on the opposite end Hungary, the Slovak Republic and Poland. DEA analysis indicates that their output could be substantially increased if they were to become located on the efficiency frontier. On average and as a conservative estimate, countries could have increased their results by 40 per cent using the same resources.

\footnotetext{
${ }^{13}$ One can briefly compare our results with the ones reported by Afonso and St. Aubyn (2005) that addressed health efficiency for 2000 using a similar set of information but without principal component analysis. Interestingly, they reported that countries labelled as efficient were: Canada, Denmark, France, Japan, Korea, Norway, Portugal, Spain, Sweden, the United Kingdom and the United States, rather along the lines of our results.
} 


\subsection{Explaining inefficiency - the role of non-discretionary inputs}

Using the DEA efficiency scores computed in the previous subsection, we now evaluate the importance of non-discretionary inputs. We present results both from Tobit regressions and bootstrap algorithms. Even if Tobit results are possibly biased, it is not clear that bootstrap estimates are necessarily more reliable. In fact, the latter are based on a set of assumptions concerning the data generation process and the perturbation term distribution that may be disputed. Taking the pros and cons of both methods into account, it seems sensible to apply both of them. If outcomes are comparable, this adds robustness and confidence to the results we are interested in.

In order to explain the efficiency scores, we regress them on GDP per capita, $Y$, educational level, $E$, obesity, $O$, and tobacco consumpion, $T$, as follows ${ }^{14}$

$$
\hat{\delta}_{i}=\beta_{0}+\beta_{1} Y_{i}+\beta_{2} E_{i}+\beta_{3} O_{i}+\beta_{4} T_{i}+\varepsilon_{i}
$$

We first report in Table 6 results from the censored normal Tobit regressions for several alternative specifications of equation (4).

\section{[Insert Table 6 here]}

Inefficiency in the health sector is strongly related to the four variables that are, at least in the short to medium run, beyond the control of governments: the economic background, proxied here by the country GDP per capita, the level of education, smoking habits, and obesity. The estimated coefficients of the first two nondiscretionary inputs are statistically significant and negatively related to the efficiency measure. For instance, an increase in education achievement reduces the efficiency score, implying that the relevant DMU moves closer to the theoretical production possibility frontier. Therefore, the better the level of education, the higher the efficiency of health provision in a given country. The same reasoning applies to GDP,

\footnotetext{
${ }^{14}$ Educational level is given by the percentage of population that achieved tertiary education in 20002003, GDP per capita refers to PPP USD in 2003, obesity refers to the percentage of obese population in 2002, and smoking refers to the percentage of population that consumed tobacco in 2003 (see the Annex for details).
} 
with higher GDP per capita resulting in more efficiency. On the other hand, efficiency is lower the stronger smoking habits are and the higher the percentage of obese population is.

We also considered other variables as non-discretionary inputs: income inequality via the Gini coefficient, the ratio of public-to-total expenditure in health, spending on pharmaceuticals as a percentage of health expenditure, percentage of population over 65 years, per capita alcohol and sugar consumption, and total calories intake. However, none of these variables prove to be statistically significant and the estimation results are not reported for the sake of space.

Table 7 reports the estimation results from the bootstrap procedures employing algorithms 1 and 2, as described in sub-section 3.3. Estimated coefficients are very similar irrespective of the algorithm used to estimate them. Moreover, they are also close to the estimates derived from the more usual Tobit procedure, and, very importantly, they are highly significant.

\section{[Insert Table 7 here]}

Significance across different model formulations and estimation methods is important and robust empirical evidence that efficiency in health depends directly on a country's wealth and on education levels, and inversely on tobacco consumption and obesity. In a nutshell, population of poorer countries where education levels are low tend to under perform, so that results are further away from the efficiency frontier. The same reasoning applies to the other two environmental factors, with higher smoking habits and obesity levels drawing countries away from health related efficient performance.

Equation (4) can be regarded as a decomposition of the output efficiency score into two distinct parts:

- the one that is the result ofIn all methods and models a country's environment, and given by $\beta_{0}+\beta_{1} Y_{i}+\beta_{2} E_{i}+\beta_{3} O_{i}+\beta_{4} T_{i}$; 
- the one that includes all other factors that have an influence on efficiency, including therefore inefficiencies associated with the health system itself, and given by $\varepsilon_{t}$.

In all methods and models, models 1,3 and 4 provide the best fit (as can be seen by the lower estimated standard deviation of $\varepsilon$ ). We choose models 1 and 3 for our exercise of correcting for environmental variables in order to use versions with and without education as an exogenous factor.

The first column in Table 8 includes the bias corrected scores for Model 1, the one with the best fit using bootstrap algorithms (as can be seen by the lower estimated standard deviation of $\varepsilon$ ). Algorithm 2 implies a bias correction after estimating output efficiency scores, taking into account the correlation between these scores and the environmental variables. We also present score corrections for the three environmental variables. GDP, obesity, and tobacco consumption corrections were computed as the changes in scores by artificially considering that $Y, O$, and $T$ varied to the sample average in each country. Fully corrected scores, presented in column five, are estimates of output scores purged from environmental effects and result from the summation of the previous four columns, truncated to one when necessary.

[Insert Table 8 here]

Comparing the ranks in the last column of Table 8, resulting from corrections for both bias and environmental variables, with the previously presented ranking from the standard DEA analysis (see Table 5 above), it is apparent that significant changes occurred. For the purpose of such comparison one should notice that the number of countries considered dropped from twenty-one in the DEA calculations to nineteen in the two-step analysis, since tobacco consumption data was not available for Austria and Portugal.

Some countries poorly ranked previously are now closer to the production possibility frontier - this is the case of Denmark, the Czech Republic, Hungary, the Slovak Republic, and the UK. On the other hand, other countries see a worsening in their 
relative position after taking into account environmental variables, namely Canada, Sweden, and the US, and to less a extent, Japan. At last, countries like Korea and Spain keep their good positioning.

Additionally, by looking at GDP, obesity and tobacco consumption corrections in Table 8, it is apparent that in some countries, environmental "harshness" essentially results from low GDP per head, as in the Czech Republic, Korea, Poland and Spain. For instance, for the US, lower than average tobacco consumption is offset by above average obesity, while for Japan, Korea, Luxembourg, and Switzerland we see an opposite pattern. Finally, note that in countries like Germany and Italy, all three environmental variables push down performance, while an inverse result can be observed for Hungary.

Alternatively, a similar analysis can be conducted for Model 3, where we now have four environmental variables: GDP, education, obesity, and tobacco consumption (see Table 9).

[Insert Table 9 here]

From the results in Table 9 it is possible to conclude that education correction is not beneficial for countries such as Canada, the US, Japan or Korea. Indeed, and as results from both Tobit and bootstrap analysis indicate, the percentage of population with tertiary education is a relevant exogenous variable in explaining health efficiency scores. On the other hand, the below average results in this variable for several other countries, such as the Czech Republic, Italy and Luxembourg, allow for an improvement in their efficiency rankings after making the corrections related to all four non-discretionary factors used in Model 3.

\section{Conclusion}

In this paper, we have evaluated efficiency in health services across countries by assessing outputs (life expectancy, infant survival rate, potential years of life not lost) against inputs directly used in the heath system (doctors, nurses, beds, MRI units) and environment variables (wealth and country education level, smoking habits and 
obesity). In methodological terms, we have employed a two-stage semi-parametric procedure. Firstly, output efficiency scores were estimated by solving a standard DEA problem with countries as DMUs. Secondly, these scores were explained in a regression with the environmental variables as independent variables.

Results from the first-stage imply that inefficiencies may be quite high. On average and as a conservative estimate, countries could have increased their results by 40 per cent using the same resources. Countries like Hungary, the Slovak Republic and Poland display significant room for improvement.

The fact that a country is seen as far away from the efficiency frontier is not necessarily a result of inefficiencies engendered within the health system. Our second stage procedures shows that GDP per head, educational attainment, tobacco consumption, and obesity are highly and significantly correlated to output scores - a wealthier and more cultivated environment are important conditions for a better health performance, while a more obese population and prevalence of smoking habits worsen health performance. Moreover, it becomes possible to correct output scores by considering the harshness of the environment where the health system operates. Country rankings and output scores derived from this correction can be substantially different from standard DEA results.

Non-discretionary outputs considered here cannot be changed in the short run. For example, educational attainment is essentially given in the coming year. However, contemporaneous educational and social policy will have an impact on future educational attainment. A similar reasoning applies to smoking habits, which are difficult to change, but where, for instance, tax measures are usually considered and implemented by the governments. Obesity problems also impinge negatively on the performance of the health system, and may be related to cultural traditions.

Finally, note that we have applied both the usual DEA/Tobit procedure and two very recently proposed bootstrap algorithms. Results were strikingly similar with these three different estimation processes, which bring increased confidence to obtained conclusions. 


\section{Appendix}

In this appendix we explain the derivation of the output variable Potential Years of Life Not Lost. According to OECD (2005), the variable Potential Years of Life Lost per 100000 population is given by:

$$
P Y L L_{t}=\sum_{a=0}^{l-1}(l-a) \frac{d_{a t}}{p_{a t}} \frac{P_{a}}{P_{n}} \times 100000,
$$

where $l$, the age limit, was set to 70 years, $d_{a t}$ is the number of deaths at age $a$ at year $t$ and $p_{a t}$ is the number of persons aged $a$ at year $t . P_{a}$ and $P_{n}$ are, respectively, the number of persons aged $a$ and the total number of persons in the reference population, the OECD total population in 1980.

Our relevant variable, Potential Years of Life Not Lost, PYLNL, is defined by us as follows:

$$
P Y L N L_{t}=\sum_{a=0}^{l-1}(l-a) \frac{p_{a t}-d_{a t}}{p_{a t}} \frac{P_{a}}{P_{n}} \times 100000 .
$$

Note that $p_{a t}-d_{a t}$ equals the number of persons aged $a$ at year $t$ that did not die.

Equation (A2) is equivalent to:

$$
\text { PYLNL }_{t}=\sum_{a=0}^{l-1}(l-a) \frac{P_{a}}{P_{n}} \times 100000-\sum_{a=0}^{l-1}(l-a) \frac{d_{a t}}{p_{a t}} \frac{P_{a}}{P_{n}} \times 100000,
$$

where the second term of the difference in the right-hand side is simply PYLL. The first term of the right-hand side of (A3) was computed by us via the very same population structure in 1980 used and reported by OECD (2005) when calculating the PYLL. It gives (see equation (3) in the text):

$$
P Y N L L=3618010-P Y L L,
$$

where 3618010 is interpretable as the number of potential years of life for a 100000 population under 70 years. 


\section{References}

Adler, N. and Golany, B. (2001). "Evaluation of deregulated airline networks using data envelopment analysis combined with principal component analysis with an application to Western Europe". European Journal of Operational Research, 132, 260-273.

Afonso, A.; Schuknecht, L. and Tanzi, V. (2005). "Public Sector Efficiency: An International Comparison," Public Choice, 123 (3-4), 321-347.

Afonso, A. and St. Aubyn (2005). "Non-parametric Approaches to Education and Health Efficiency in OECD Countries," Journal of Applied Economics, 8 (2), 227 246.

Afonso, A. and St. Aubyn (2006). "Cross-country Efficiency of Secondary Education Provision: a Semi-parametric Analysis with Non-discretionary Inputs," Economic Modelling, 23 (3), 476-491.

Charnes, A.; Cooper, W. and Rhodes, E. (1978). "Measuring the efficiency of decision making units," European Journal of Operational Research, 2 (6), 429-444.

Coelli, T.; Rao, P., O'Donnell, C. and Battese, G. (2005). An Introduction to Efficiency and Productivity Analysis. Kluwer, Boston.

EC (2004). Public Finances in EMU - 2004. A report by the Commission services, SEC(2004) 761. Brussels.

Evans, D.; Tandon, A.; Murray, C. and Lauer, J. (2000). "The Comparative Efficiency of National Health Systems in Producing Health: an Analysis of 191 Countries", GPE Discussion Paper Series 29, Geneva, World Health Organisation.

Everitt, B. and Dunn, G. (2001). Applied Multivariate Data analysis, $2^{\text {nd }}$ edition, Arnold, London.

Farrell, M. (1957). "The Measurement of Productive Efficiency," Journal of the Royal Statistical Society, Series A, 120, Part 3, 253-290.

Gupta, S. and Verhoeven, M. (2001). "The Efficiency of Government Expenditure Experiences from Africa", Journal of Policy Modelling, 23, 433-467.

Jollife, I. (1972) "Discarding variables in a principal component analysis 1: Artificial data", Applied Statistics, 21, 160-173.

OECD (2003). "Enhancing the Cost Effectiveness of Public Spending," in Economic Outlook, vol. 2003/02, n. 74, December, OECD.

OECD (2005), OECD Health Data 2005, Paris, OECD.

Retzlaff-Roberts, D., Chang, C. and Rubin, R. (2004). "Technical efficiency in the use of health care resources: a comparison of OECD countries, Health Policy, 69, 55-72. 
Ruggiero, J. (2004). "Performance evaluation when non-discretionary factors correlate with technical efficiency", European Journal of Operational Research 159, 250-257.

Simar, L. and Wilson, P. (2000). "A General Methodology for Bootstrapping in Nonparametric Frontier Models”, Journal of Applied Statistics 27, 779-802.

Simar, L. and Wilson, P. (2007). "Estimation and Inference in Two-Stage, SemiParametric Models of Production Processes", Journal of Econometrics 136 (1), 31-64.

Spinks, J. and Hollingsworth, B. (2005). "Health production and the socioeconomic determinants of health in OECD countries: the use of efficiency models", Monash University, Center for Health Economics, Working Paper 151.

Thanassoulis, E. (2001). Introduction to the Theory and Application of Data Envelopment Analysis, Kluwer Academic Publishers. 


\section{Annex - Data and sources}

Table A1. Health indicators

\begin{tabular}{|c|c|c|c|c|c|c|c|}
\hline Country & $\begin{array}{c}\text { Life } \\
\text { expectancy } \\
1 / \\
\end{array}$ & $\begin{array}{c}\text { Infant } \\
\text { mortality } \\
2 /\end{array}$ & $\begin{array}{c}\text { Potential } \\
\text { years of life } \\
\text { lost 3/ }\end{array}$ & $\begin{array}{c}\text { Practising } \\
\text { physicians } \\
4 / \\
\end{array}$ & $\begin{array}{c}\text { Practising } \\
\text { nurses } \\
5 /\end{array}$ & $\begin{array}{c}\text { Acute care } \\
\text { beds } \\
6 /\end{array}$ & $\begin{array}{c}\text { MRI units } \\
7 /\end{array}$ \\
\hline Australia & 79.8 & 5.0 & 3502 & 2.5 & 10.4 & 3.7 & 3.7 \\
\hline Austria & 78.4 & 4.5 & 3700 & 3.3 & 9.3 & 6.1 & 12.4 \\
\hline Belgium & 77.9 & 4.4 &.. & 3.9 & 5.6 & 4.0 & 6.6 \\
\hline Canada & 79.5 & 5.3 & 3554 & 2.1 & 9.8 & 3.2 & 3.9 \\
\hline Czech Republic & 75.2 & 4.0 & 4632 & 3.5 & 9.2 & 6.5 & 2.1 \\
\hline Denmark & 77.1 & 4.6 & 4014 & 2.9 & 10.2 & 3.4 & 7.1 \\
\hline Finland & 78.1 & 3.1 & 3907 & 2.6 & 8.8 & 2.4 & 11.6 \\
\hline France & 79.2 & 4.2 & 4098 & 3.3 & 7.1 & 4.0 & 2.6 \\
\hline Germany & 78.2 & 4.2 & 3736 & 3.3 & 9.6 & 6.7 & 5.7 \\
\hline Greece & 78.1 & 5.0 & 3601 & 4.4 & 3.9 &.. & 2.2 \\
\hline Hungary & 72.1 & 7.5 & 7056 & 3.2 & 5.0 & 6.0 & 2.3 \\
\hline Iceland & 80.2 & 2.4 & 3054 & 3.5 & 13.4 &.. & 14.9 \\
\hline Ireland & 77.2 & 5.3 & 4225 & 2.4 & 14.7 & 3.0 &.. \\
\hline Italy & 79.8 & 4.5 & 3287 & 4.3 & 5.4 & 4.0 & 9.6 \\
\hline Japan & 81.5 & 3.0 & 2917 & 2.0 & 7.7 & 9.1 & 32.3 \\
\hline Korea & 76.2 & 6.2 & 4426 & 1.5 & 1.6 & 5.5 & 7.3 \\
\hline Luxembourg & 78.1 & 5.3 & 3939 & 2.6 & 10.3 & 5.8 & 6.2 \\
\hline Mexico & 74.5 & 21.3 &.. & 1.5 & 2.2 & 1.0 & 0.2 \\
\hline Netherlands & 78.3 & 5.1 & 3447 & 3.2 & 13.0 & 3.3 &.. \\
\hline New Zealand & 78.7 & 5.6 & 4149 & 2.2 & 9.4 &.. & 3.4 \\
\hline Norway & 79.1 & 3.6 & 3515 & 3.0 & 10.4 & 3.1 &.. \\
\hline Poland & 74.3 & 7.4 & 5974 & 2.3 & 4.9 & 5.0 & 0.9 \\
\hline Portugal & 77.0 & 4.7 & 4934 & 3.3 & 3.9 & 3.2 & 3.6 \\
\hline Slovak Republic & 73.6 & 7.2 & 5879 & 3.1 & 7.0 & 6.2 & 2.0 \\
\hline Spain & 79.8 & 4.2 & 3597 & 3.1 & 7.0 & 3.2 & 6.0 \\
\hline Sweden & 80.0 & 3.4 & 2937 & 3.2 & 10.0 & 2.4 & 7.9 \\
\hline Switzerland & 80.1 & 4.6 & 3339 & 3.6 & 10.7 & 4.0 & 13.5 \\
\hline Turkey & 68.4 & 36.3 &.. & 1.4 & 1.7 & 2.2 & 3.0 \\
\hline United Kingdom & 78.2 & 5.3 & 3721 & 2.1 & 8.7 & 3.7 & 5.1 \\
\hline United States & 77.0 & 6.9 & 5101 & 2.3 & 7.9 & 2.9 & 8.4 \\
\hline Mean & 77.5 & 6.5 & 4083 & 2.8 & 8.0 & 4.2 & 6.8 \\
\hline Median & 78.2 & 4.9 & 3736 & 3.1 & 8.8 & 3.7 & 5.7 \\
\hline Minimum & 68.4 & 2.4 & 2917 & 1.4 & 1.6 & 1.0 & 0.2 \\
\hline Maximum & 81.5 & 36.3 & 7056 & 4.4 & 14.7 & 9.1 & 32.3 \\
\hline Standard deviation & 2.8 & 6.5 & 981.2 & 0.8 & 3.4 & 1.8 & 6.4 \\
\hline Observations & 30 & 30 & 27 & 30 & 30 & 27 & 27 \\
\hline
\end{tabular}

1/ Years of life expectancy, total population at birth. Average for 2000 and 2003. Source: OECD (2005).

2/ Deaths per 1000 live births. Average for 2000-2003. Source: OECD (2005).

3/ All causes - $<70$ year,/100 000. Average for 2000-2003. Source: OECD (2005).

4/ 5/ 6/ Density per 1000 population. Average for 2000-2003. Source: OECD (2005).

7/ Per million population. Average for 2000-2003. Source: OECD (2005).

.. - non available. 
Table A2. Non-discretionary factors

\begin{tabular}{|c|c|c|c|c|}
\hline Country & $\begin{array}{c}\text { Per capita GDP } \\
1 /\end{array}$ & $\begin{array}{c}\text { Education level } \\
2 /\end{array}$ & $\begin{array}{c}\text { Obesity } \\
3 /\end{array}$ & $\begin{array}{c}\text { Tobacco } \\
4 /\end{array}$ \\
\hline Australia & 29143 & 19.5 & $21.7^{\#}$ & $19.8^{\$}$ \\
\hline Austria & 29972 & 7.0 & $9.1^{\#}$ &.. \\
\hline Belgium & 28396 & 12.7 & $11.7^{\$}$ & 27.0 \\
\hline Canada & 30463 & 20.8 & $14.3 *$ & 17.0 \\
\hline Czech Republic & 16448 & 11.4 & 14.8 & $24.1 *$ \\
\hline Denmark & 31630 & 12.0 & $9.5^{\#}$ & 28.0 \\
\hline Finland & 27252 & 15.4 & $12.8 *$ & 22.2 \\
\hline France & 27327 & 12.5 & 9.4 & 27.0 \\
\hline Germany & 27609 & 13.6 & $12.9 *$ & 24.3 \\
\hline Greece & 19973 & 12.2 & 21.9 & $35.0^{\#}$ \\
\hline Hungary & 14572 & 14.4 & $18.8 *$ & 33.8 \\
\hline Iceland & 30657 & 18.9 & 12.4 & 22.4 \\
\hline Ireland & 36775 & 14.3 & 13.0 & $27.0 *$ \\
\hline Italy & 27050 & 10.0 & 8.5 & 24.2 \\
\hline Japan & 28162 & 20.1 & $3.2 *$ & 30.3 \\
\hline Korea & 17908 & 18.9 & $3.2^{\$}$ & $30.4^{\$}$ \\
\hline Luxembourg & 62844 & 10.2 & 18.4 & 33.0 \\
\hline Mexico & 9136 & 13.4 & 24.2 & $26.4^{*}$ \\
\hline Netherlands & 29412 & 21.2 & 10.0 & 32.0 \\
\hline New Zealand & 21177 & 14.6 & $20.9 *$ & 25.0 \\
\hline Norway & 37063 & 27.5 & 8.3 & 26.0 \\
\hline Poland & 11623 & 12.5 & $11.4^{\&}$ & $27.6^{\$}$ \\
\hline Portugal & 18444 & 7.1 & 12.8 &.. \\
\hline Slovak Republic & 13469 & 10.4 & 22.4 & $24.3^{*}$ \\
\hline Spain & 22264 & 17.1 & $13.1 *$ & 28.1 \\
\hline Sweden & 26656 & 16.8 & $9.7 *$ & 17.5 \\
\hline Switzerland & 30186 & 16.1 & 7.7 & $26.8 *$ \\
\hline Turkey & 6749 & 8.9 & $12.0 *$ & 32.1 \\
\hline United Kingdom & 27106 & 18.3 & $23.0 *$ & 26.0 \\
\hline United States & 37352 & 28.7 & 30.6 & 17.5 \\
\hline Mean & 25894 & 15.2 & 14.1 & 26.2 \\
\hline Median & 27290 & 14.4 & 12.8 & 26.6 \\
\hline Minimum & 6749 & 7.0 & 3.2 & 17.0 \\
\hline Maximum & 62844 & 28.7 & 30.6 & 35.0 \\
\hline Standard deviation & 10681 & 5.2 & 6.4 & 4.8 \\
\hline Observations & 30 & 30 & 30 & 28 \\
\hline
\end{tabular}

1/ GDP per capita - (USD) PPP GDP and population in 2003. Source: World Development Indicators Database, September 2003.

2/ Percentage of population at ISCED 5A = Programmes at the tertiary level equivalent to university programmes (ISCED-76: level 6), and ISCED $6=$ Advanced research programmes at the tertiary level, equivalent to $\mathrm{PhD}$ programmes. (ISCED-76: level 7). Average for 2000-2003. Source: OECD, Education at a Glance 2005, www.oecd.org/edu/eag2005.

3/ 2002 body weight, obese population (BMI $>30 \mathrm{~kg} / \mathrm{m} 2$ ). Source: OECD HEALTH DATA 2005, Sept. 05. ${ }^{*}-2003 ;{ }^{\$}-2001 ;{ }^{\#} 1999 ;$ \& -1996.

4/ Tobacco consumption (\% of pop), 2003. Source: OECD HEALTH DATA 2005, Sept. 05. * - 2002; $\$$ $-2001 ;{ }^{\#} 2000$.

.. - non available. 
Tables and figures

Table 1 - Public and total expenditure on health

\begin{tabular}{|c|c|c|c|c|c|c|}
\hline & \multicolumn{2}{|c|}{$\begin{array}{c}\text { Total expenditure, } \\
\% \text { of GDP }\end{array}$} & \multicolumn{2}{|c|}{$\begin{array}{l}\text { Public expenditure, } \\
\% \text { of total expenditure }\end{array}$} & \multicolumn{2}{|c|}{$\begin{array}{l}\text { Total health expenditure } \\
\text { per capita US\$ PPP }\end{array}$} \\
\hline & 1995 & 2003 & 1995 & 2003 & 1995 & 2003 \\
\hline Australia & 8.3 & 9.3 & 66.7 & 67.5 & 1745 & 2699 \\
\hline Austria & 8.5 & 7.5 & 69.7 & 67.6 & 1973 & 2302 \\
\hline Belgium & 8.4 & 9.6 &.. &.. & 1820 & 2827 \\
\hline Canada & 9.2 & 9.9 & 71.4 & 69.9 & 2051 & 3001 \\
\hline Czech Republic & 6.9 & 7.5 & 92.7 & 90.1 & 873 & 1298 \\
\hline Denmark & 8.2 & 9.0 & 82.5 & 83.0 & 1848 & 2763 \\
\hline Finland & 7.5 & 7.4 & 75.6 & 76.5 & 1433 & 2118 \\
\hline France & 9.5 & 10.1 & 76.3 & 76.3 & 2033 & 2903 \\
\hline Germany & 10.6 & 11.1 & 80.5 & 78.2 & 2276 & 2996 \\
\hline Greece & 9.6 & 9.9 & 52.0 & 51.3 & 1253 & 2011 \\
\hline Hungary & 7.5 & 8.4 & 84.0 & 72.4 & 676 & 1269 \\
\hline Iceland & 8.4 & 10.5 & 83.9 & 83.5 & 1858 & 3115 \\
\hline Ireland & 6.8 & 7.4 & 71.6 & 78.0 & 1216 & 2451 \\
\hline Italy & 7.3 & 8.4 & 71.9 & 75.1 & 1535 & 2258 \\
\hline Japan & 6.8 & 7.9 & 83.0 & 81.5 & 1538 & 2139 \\
\hline Korea & 4.2 & 5.6 & 35.3 & 49.4 & 538 & 1074 \\
\hline Luxembourg & 6.4 & 6.9 & 92.4 & 89.9 & 2059 & 3705 \\
\hline Mexico & 5.6 & 6.2 & 42.1 & 46.4 & 382 & 583 \\
\hline Netherlands & 8.4 & 9.8 & 71.0 & 62.4 & 1826 & 2976 \\
\hline New Zealand & 7.2 & 8.1 & 77.2 & 78.7 & 1247 & 1886 \\
\hline Norway & 7.9 & 10.3 & 84.2 & 83.7 & 1897 & 3807 \\
\hline Poland & 5.6 & 6.5 & 72.9 & 69.9 & 417 & 744 \\
\hline Portugal & 8.2 & 9.6 & 62.6 & 69.7 & 1079 & 1797 \\
\hline Slovak Republic & 5.8 & 5.9 & 91.7 & 88.3 & 543 & 777 \\
\hline Spain & 7.6 & 7.7 & 72.2 & 71.2 & 1198 & 1835 \\
\hline Sweden & 8.1 & 9.4 & 86.6 & 85.2 & 1738 & 2703 \\
\hline Switzerland & 9.7 & 11.5 & 53.8 & 58.5 & 2579 & 3781 \\
\hline Turkey & 3.4 & 7.4 & 70.3 & 70.9 & 185 & 513 \\
\hline United Kingdom & 7.0 & 7.7 & 83.9 & 83.4 & 1374 & 2231 \\
\hline United States & 13.3 & 15.0 & 45.3 & 44.4 & 3654 & 5635 \\
\hline Mean & 7.7 & 8.7 & 72.5 & 72.5 & 1494.8 & 2340 \\
\hline Median & 7,8 & 8,4 & 72,9 & 75,1 & 1536,5 & 2280 \\
\hline Standard deviation & 1,9 & 2,0 & 14,9 & 12,7 & 738,7 & 1115 \\
\hline Minimum & $\begin{array}{c}3.4 \\
\text { (TUR) }\end{array}$ & $\begin{array}{c}5.6 \\
(\mathrm{KOR})\end{array}$ & $\begin{array}{c}35.3 \\
(\mathrm{KOR})\end{array}$ & $\begin{array}{l}44.4 \\
\text { (US) }\end{array}$ & $\begin{array}{c}185.0 \\
\text { (TUR) }\end{array}$ & $\begin{array}{c}513 \\
\text { (TUR) }\end{array}$ \\
\hline Maximum & $\begin{array}{l}13.3 \\
\text { (US) } \\
\end{array}$ & $\begin{array}{l}15.0 \\
\text { (US) } \\
\end{array}$ & $\begin{array}{l}92.7 \\
(\mathrm{CZ}) \\
\end{array}$ & $\begin{array}{l}90.1 \\
(\mathrm{CZ}) \\
\end{array}$ & $\begin{array}{c}3654.0 \\
\text { (US) }\end{array}$ & $\begin{array}{l}5635 \\
\text { (US) } \\
\end{array}$ \\
\hline EU 15 average & 8.1 & 8.8 & 69.9 & 69.9 & 1644.1 & 2525 \\
\hline
\end{tabular}

Sources: OECD Health Data 2005 - Frequently asked data (http://www.oecd.org/document/16/0,2340,en_2825_495642_2085200_1_1_1_1,00.html). .. - non available. 
Table 2 - Summary statistics of the input and output data

\begin{tabular}{|c|c|c|c|c|}
\hline & Mean & $\begin{array}{l}\text { Standard } \\
\text { deviation }\end{array}$ & Minimum & Maximum \\
\hline Life expectancy (in years) 1/ & 77.5 & 2.8 & $\begin{array}{c}68.4 \\
\text { (TUR) }\end{array}$ & $\begin{array}{c}81.5 \\
\text { (JAP) }\end{array}$ \\
\hline $\begin{array}{l}\text { Infant mortality rate (deaths per } \\
1000 \text { live births) } 2 /\end{array}$ & 4.5 & 6.5 & $\begin{array}{c}2.4 \\
(\mathrm{ICE})\end{array}$ & $\begin{array}{l}36.3 \\
\text { (TUR) }\end{array}$ \\
\hline $\begin{array}{l}\text { Potential years of life lost (All } \\
\text { causes - <70 year,/100 000) } 2 /\end{array}$ & 4083 & 981.2 & $\begin{array}{l}2917 \\
(J A P)\end{array}$ & $\begin{array}{l}7056 \\
(\mathrm{HU})\end{array}$ \\
\hline $\begin{array}{l}\text { Practising physicians, density per } \\
1000 \text { population } 2 /\end{array}$ & 2.8 & 0.8 & $\begin{array}{c}1.4 \\
\text { (TUR) }\end{array}$ & $\begin{array}{c}4.4 \\
(\mathrm{GRC})\end{array}$ \\
\hline $\begin{array}{l}\text { Practising nurses, density per } 1000 \\
\text { population } 2 /\end{array}$ & 8.0 & 3.4 & $\begin{array}{c}1.6 \\
(\mathrm{KOR})\end{array}$ & $\begin{array}{l}14.7 \\
(\text { IRE })\end{array}$ \\
\hline $\begin{array}{l}\text { Acute care beds, density per } 1000 \\
\text { population } 2 /\end{array}$ & 4.2 & 1.8 & $\begin{array}{c}1.0 \\
(\mathrm{MEX})\end{array}$ & $\begin{array}{c}9.1 \\
(\mathrm{JAP})\end{array}$ \\
\hline $\begin{array}{l}\text { MRI units, per million population } \\
2 /\end{array}$ & 6.8 & 6.4 & $\begin{array}{c}0.2 \\
(\mathrm{MEX})\end{array}$ & $\begin{array}{c}32.3 \\
(\mathrm{JAP})\end{array}$ \\
\hline
\end{tabular}

Notes: 1/ Average for 2000 and 2003. 2/ Average for 2000-2003.

TUR - Turkey; JAP - Japan; ICE - Iceland; HU - Hungary; GCR - Greece; KOR - Korea; IRE - Ireland; MEX - Mexico.

Table 3 - Eigenvalues and cumulative R-squared of PCA on health input and output indicators

\begin{tabular}{ccccc}
\hline & \multicolumn{2}{c}{$\begin{array}{c}\text { Input indicators } \\
\text { (doctors, nurse, beds, and MRI } \\
\text { units) }\end{array}$} & $\begin{array}{c}\text { Output indicators (life expectancy, } \\
\text { infant survival rate, and potential } \\
\text { number of years of life not lost) }\end{array}$ \\
\hline Component & Eigenvalue & $\begin{array}{c}\text { Cumulative R- } \\
\text { Squared }\end{array}$ & Eigenvalue & $\begin{array}{c}\text { Cumulative R- } \\
\text { Squared }\end{array}$ \\
\hline 1 & 1.0799 & 0.4275 & 2.5155 & 0.8385 \\
2 & 1.1208 & 0.7077 & 0.4210 & 0.9789 \\
3 & 0.7071 & 0.8845 & $0.6342 \mathrm{E}-01$ & 1.0000 \\
4 & 0.4621 & 1.0000 & & \\
\hline
\end{tabular}


Table 4 - Principal components used in the DEA calculations

\begin{tabular}{|c|c|c|c|c|}
\hline & Output & & Input & \\
\hline & P1 & $\mathrm{P} 1$ & P2 & $\mathrm{P} 3$ \\
\hline Australia & 4.093 & 3.338 & 4.886 & 1.343 \\
\hline Austria & 3.890 & 4.591 & 4.333 & 2.641 \\
\hline Belgium & & 3.452 & 5.160 & 3.584 \\
\hline Canada & 3.971 & 3.007 & 4.546 & 1.055 \\
\hline Czech Republic & 3.125 & 4.084 & 5.151 & 3.412 \\
\hline Denmark & 3.496 & 3.593 & 4.934 & 1.385 \\
\hline Finland & 4.222 & 3.329 & 4.401 & 1.000 \\
\hline France & 3.972 & 3.178 & 5.177 & 2.962 \\
\hline Germany & 3.921 & 4.340 & 4.792 & 3.120 \\
\hline Greece & 3.735 & & & \\
\hline Hungary & 1.000 & 3.293 & 4.455 & 4.182 \\
\hline Iceland & 5.381 & & & \\
\hline Ireland & 3.280 & & & \\
\hline Italy & 4.302 & 3.756 & 5.224 & 3.739 \\
\hline Japan & 5.296 & 5.778 & 1.000 & 2.265 \\
\hline Korea & 2.921 & 2.369 & 2.303 & 3.501 \\
\hline Luxembourg & 3.602 & 3.992 & 4.382 & 2.055 \\
\hline Mexico & & 1.000 & 3.757 & 2.116 \\
\hline Netherlands & 3.856 & & & \\
\hline New Zealand & 3.526 & & & \\
\hline Norway & 4.380 & & & \\
\hline Poland & 1.829 & 2.645 & 4.016 & 3.324 \\
\hline Portugal & 3.093 & 2.601 & 4.780 & 3.427 \\
\hline Slovak Republic & 1.762 & 3.587 & 4.658 & 3.680 \\
\hline Spain & 4.299 & 3.110 & 4.859 & 2.395 \\
\hline Sweden & 4.871 & 3.520 & 5.345 & 1.280 \\
\hline Switzerland & 4.301 & 4.447 & 5.006 & 1.612 \\
\hline Turkey & & 1.316 & 3.135 & 2.412 \\
\hline United Kingdom & 3.668 & 3.026 & 4.188 & 1.440 \\
\hline United States & 2.707 & 3.006 & 4.148 & 1.334 \\
\hline
\end{tabular}

Note: The original principal components data were increased by the most negative value plus one, in order to ensure strictly positive data. 
Table 5 - DEA output efficiency results for health efficiency in OECD countries, 3 inputs (PCA on doctors, nurses, beds and MRI) and 1 output (PCA on life expectancy, infant survival rate, and potential number of years of life not lost)

\begin{tabular}{lcccc}
\hline \multicolumn{1}{c}{ Country } & VRS TE & Rank & Peers & Rank 2 \\
\hline Australia & 1.101 & 10 & Canada, Sweden, Korea, Finland & 10 \\
Austria & 1.304 & 15 & Sweden, Japan & 15 \\
Canada & 1.000 & 1 & Canada & 6 \\
Czech Republic & 1.592 & 18 & Japan, Sweden & 18 \\
Denmark & 1.368 & 16 & Korea, Japan, Sweden, Finland & 16 \\
\hline Finland & 1.000 & 1 & Finland & 4 \\
France & 1.106 & 11 & Sweden, Spain & 11 \\
Germany & 1.282 & 14 & Sweden, Japan & 14 \\
Hungary & 4.386 & 21 & Sweden, Japan, Korea & 21 \\
Italy & 1.143 & 12 & Sweden, Japan & 12 \\
\hline Japan & 1.000 & 1 & Japan & 2 \\
Korea & 1.000 & 1 & Korea & 3 \\
Luxembourg & 1.372 & 17 & Korea, Japan, Sweden & 17 \\
Poland & 1.876 & 19 & Spain, Korea & 19 \\
Portugal & 1.083 & 9 & Korea, Spain & 9 \\
\hline Slovak Republic & 2.667 & 20 & Korea, Sweden, Japan & 20 \\
Spain & 1.000 & 1 & Spain & 4 \\
Sweden & 1.000 & 1 & Sweden & 1 \\
Switzerland & 1.166 & 13 & Sweden, Japan & 13 \\
\hline United Kingdom & 1.070 & 8 & Canada, Sweden, Korea, Finland & 8 \\
United States & 1.000 & 1 & United States & 7 \\
\hline Average & 1.406 & & & \\
\hline & & & & \\
\hline
\end{tabular}

Note: VRS TE - variable returns to scale technical efficiency. Rank 2 - ranking taking into account the number of times the efficient countries are peers of inefficient countries. 
Table 6 - Censored normal Tobit results (19 countries)

\begin{tabular}{lcccc}
\hline & Model 1 & Model 2 & Model 3 & Model 4 \\
\hline Constant & -3.2574 & 9.0162 & -1.1185 & 9.9146 \\
$Y$ & $(0.000)$ & $(0.029)$ & $(0.092)$ & $(0.009)$ \\
& $-4.38 \mathrm{E}-05$ & & $-4.44 \mathrm{E}-05$ & \\
$\log (Y)$ & $(0.000)$ & & $(0.000)$ & -1.1546 \\
$E$ & & -1.2476 & & $(0.000)$ \\
& & $(0.000)$ & & -0.0891 \\
$O$ & & & -0.1060 & $(0.034)$ \\
$T$ & 0.0895 & 0.0783 & $(0.010)$ & 0.0841 \\
$T$ & $(0.000)$ & $(0.001)$ & 0.0946 & $(0.000)$ \\
& 0.1708 & 0.1453 & 0.1463 & 0.122 \\
$\hat{\sigma}_{\varepsilon}$ & $(0.000)$ & $(0.000)$ & $(0.000)$ & $(0.001)$ \\
\hline
\end{tabular}

Notes: $Y$ - GDP per capita; $E$ - Educational level; O - Obesity; T - Tobacco consumption. $\hat{\sigma}_{\varepsilon}-$ Estimated standard deviation of $\varepsilon$. P- values in brackets. 
Table 7 - Bootstrap results (19 countries)

\begin{tabular}{|c|c|c|c|c|}
\hline \multicolumn{5}{|c|}{ Algorithm 1} \\
\hline & Model 1 & Model 2 & Model 3 & Model 4 \\
\hline Constant & $\begin{array}{l}-6.6028 \\
(0.009)\end{array}$ & $\begin{array}{l}7.6945 \\
(0.022)\end{array}$ & $\begin{array}{l}-1.2825 \\
(0.087)\end{array}$ & $\begin{array}{l}8.3628 \\
(0.027)\end{array}$ \\
\hline$Y$ & $\begin{array}{c}-10.58 \mathrm{E}-05 \\
(0.026)\end{array}$ & & $\begin{array}{c}-4.729 \mathrm{E}-05 \\
(0.000)\end{array}$ & \\
\hline $\log (Y)$ & & $\begin{array}{c}-1.6889 \\
(0.015)\end{array}$ & & $\begin{array}{c}-1.8438 \\
(0.005)\end{array}$ \\
\hline$E$ & & & $\begin{array}{l}-0.1533 \\
(0.000)\end{array}$ & $\begin{array}{c}-0.06016 \\
(0.029)\end{array}$ \\
\hline$O$ & $\begin{array}{l}0.1430 \\
(0.012)\end{array}$ & $\begin{array}{r}0.0900 \\
(0.033)\end{array}$ & $\begin{array}{r}0.09536 \\
(0.000)\end{array}$ & $\begin{array}{l}0.2036 \\
(0.010)\end{array}$ \\
\hline$T$ & $\begin{array}{l}0.2874 \\
(0.010)\end{array}$ & $\begin{array}{l}0.1341 \\
(0.072)\end{array}$ & $\begin{array}{l}0.1686 \\
(0.000)\end{array}$ & $\begin{array}{l}0.1155 \\
(0.053)\end{array}$ \\
\hline$\hat{\sigma}_{\varepsilon}$ & $\begin{array}{l}0.4910 \\
(0.000)\end{array}$ & $\begin{array}{c}0.762 \\
(0.010) \\
\end{array}$ & $\begin{array}{l}0.3746 \\
(0.000) \\
\end{array}$ & $\begin{array}{l}0.7518 \\
(0.007) \\
\end{array}$ \\
\hline \multicolumn{5}{|c|}{ Algorithm 2} \\
\hline Constant & $\begin{array}{c}-6.5738 \\
(0.006)\end{array}$ & $\begin{array}{l}7.3501 \\
(0.011)\end{array}$ & $\begin{array}{r}-1.4814 \\
(0.128)\end{array}$ & $\begin{array}{l}9.9388 \\
(0.022)\end{array}$ \\
\hline$Y$ & $\begin{array}{c}-10.61 \mathrm{E}-05 \\
(0.030)\end{array}$ & & $\begin{array}{c}-5.0726 \mathrm{E}-05 \\
(0.002)\end{array}$ & \\
\hline $\log (Y)$ & & $\begin{array}{r}-1.6866 \\
(0.002)\end{array}$ & & $\begin{array}{l}-2.0641 \\
(0.005)\end{array}$ \\
\hline$E$ & & & $\begin{array}{l}-0.2160 \\
(0.007)\end{array}$ & $\begin{array}{c}-0.06656 \\
(0.068)\end{array}$ \\
\hline$O$ & $\begin{array}{l}0.1431 \\
(0.011)\end{array}$ & $\begin{array}{c}0.09182 \\
(0.005)\end{array}$ & $\begin{array}{l}0.0908 \\
(0.004)\end{array}$ & $\begin{array}{l}0.1921 \\
(0.007)\end{array}$ \\
\hline$T$ & $\begin{array}{l}0.2878 \\
(0.009)\end{array}$ & $\begin{array}{l}0.1376 \\
(0.004)\end{array}$ & $\begin{array}{l}0.1963 \\
(0.000)\end{array}$ & $\begin{array}{l}0.1287 \\
(0.048)\end{array}$ \\
\hline$\hat{\sigma}_{\varepsilon}$ & $\begin{array}{l}0.4876 \\
(0.000) \\
\end{array}$ & $\begin{array}{l}0.7622 \\
(0.005) \\
\end{array}$ & $\begin{array}{l}0.6040 \\
(0.000) \\
\end{array}$ & $\begin{array}{c}0.84062 \\
(0.006) \\
\end{array}$ \\
\hline
\end{tabular}

Notes: $Y$ - GDP per capita; $E$ - Educational level; O - Obesity; T - Tobacco consumption. $\hat{\sigma}_{\varepsilon}-$ Estimated standard deviation of $\varepsilon$. P- values in brackets. 
Table 8 - Corrected output efficiency scores (for Model 1)

\begin{tabular}{|c|c|c|c|c|c|c|}
\hline & $\begin{array}{l}\text { Bias } \\
\text { corrected } \\
\text { scores } \\
(1)\end{array}$ & $\begin{array}{c}\text { GDP } \\
\text { correction } \\
(2)\end{array}$ & $\begin{array}{c}\text { Obesity } \\
\text { correction } \\
\text { (3) }\end{array}$ & $\begin{array}{c}\text { Tobacco } \\
\text { correction } \\
\text { (4) }\end{array}$ & $\begin{array}{c}\text { Fully } \\
\text { corrected } \\
\text { scores } \\
(5)=(1)+(2)+ \\
(3)+(4)\end{array}$ & Rank \\
\hline Australia & 1.144 & 0.249 & -1.106 & 1.601 & 1.889 & 12 \\
\hline Canada & 1.102 & 0.389 & -0.047 & 2.407 & 3.851 & 18 \\
\hline Czech Republic & 1.640 & -1.098 & -0.119 & 0.364 & 1.000 & 1 \\
\hline Denmark & 1.428 & 0.513 & 0.639 & -0.759 & 1.822 & 10 \\
\hline Finland & 1.091 & 0.049 & 0.167 & 0.910 & 2.217 & 15 \\
\hline France & 1.157 & 0.057 & 0.654 & -0.471 & 1.396 & 9 \\
\hline Germany & 1.326 & 0.087 & 0.153 & 0.306 & 1.871 & 11 \\
\hline Hungary & 4.597 & -1.297 & -0.691 & -2.428 & 1.000 & 1 \\
\hline Italy & 1.180 & 0.027 & 0.783 & 0.335 & 2.325 & 16 \\
\hline Japan & 1.125 & 0.145 & 1.541 & -1.421 & 1.391 & 8 \\
\hline Korea & 1.180 & -0.943 & 1.541 & -1.450 & 1.000 & 1 \\
\hline Luxembourg & 1.432 & 3.825 & -0.634 & -2.198 & 2.425 & 17 \\
\hline Poland & 2.092 & -1.610 & 0.368 & -0.644 & 1.000 & 1 \\
\hline Slovak Republic & 2.768 & -1.414 & -1.207 & 0.306 & 1.000 & 1 \\
\hline Spain & 1.057 & -0.481 & 0.124 & -0.788 & 1.000 & 1 \\
\hline Sweden & 1.070 & -0.015 & 0.611 & 2.263 & 3.930 & 19 \\
\hline Switzerland & 1.222 & 0.360 & 0.897 & -0.414 & 2.065 & 13 \\
\hline United Kingdom & 1.141 & 0.033 & -1.292 & -0.183 & 1.000 & 1 \\
\hline United States & 1.079 & 1.120 & -2.380 & 2.263 & 2.083 & 14 \\
\hline Average & 1.518 & 0.000 & 0.000 & 0.000 & 1.803 & \\
\hline
\end{tabular}

Note: the fully corrected scores do not always add up to the indicated sum since for the cases were the result was below one we truncated it to the unity. 
Table 9 - Corrected output efficiency scores (for Model 3)

\begin{tabular}{lccccccc}
\hline & $\begin{array}{c}\text { Bias } \\
\text { corrected } \\
\text { scores } \\
(1)\end{array}$ & $\begin{array}{c}\text { GDP } \\
\text { correction }\end{array}$ & $\begin{array}{c}\text { Education } \\
\text { correction }\end{array}$ & $\begin{array}{c}\text { Obesity } \\
\text { correction }\end{array}$ & $\begin{array}{c}\text { Tobacco } \\
\text { correction }\end{array}$ & $\begin{array}{c}\text { Fully } \\
\text { corrected } \\
\text { scores }\end{array}$ & Rank \\
& & $(2)$ & $(3)$ & $(4)$ & $(5)$ & $\begin{array}{c}(1)+(2)+ \\
(3)+(4)+(5)\end{array}$ \\
\hline Australia & 1.145 & 0.119 & 0.816 & -0.702 & 1.092 & 2.470 & 16 \\
Canada & 1.055 & 0.186 & 1.097 & -0.030 & 1.642 & 3.949 & 18 \\
Czech Republic & 1.654 & -0.525 & -0.933 & -0.076 & 0.248 & 1.000 & 1 \\
Denmark & 1.430 & 0.245 & -0.804 & 0.406 & -0.518 & 1.000 & 1 \\
Finland & 1.102 & 0.023 & -0.069 & 0.106 & 0.621 & 1.783 & 14 \\
France & 1.167 & 0.027 & -0.696 & 0.415 & -0.321 & 1.000 & 1 \\
Germany & 1.333 & 0.041 & -0.458 & 0.097 & 0.209 & 1.222 & 10 \\
Hungary & 4.595 & -0.620 & -0.285 & -0.439 & -1.656 & 1.595 & 12 \\
Italy & 1.186 & 0.013 & -1.236 & 0.497 & 0.228 & 1.000 & 1 \\
Japan & 1.078 & 0.069 & 0.946 & 0.978 & -0.969 & 2.102 & 15 \\
Korea & 1.126 & -0.451 & 0.687 & 0.978 & -0.989 & 1.351 & 11 \\
Luxembourg & 1.440 & 1.829 & -1.193 & -0.402 & -1.499 & 1.000 & 1 \\
Poland & 2.050 & -0.770 & -0.696 & 0.233 & -0.439 & 1.000 & 1 \\
Slovak Republic & 2.781 & -0.676 & -1.149 & -0.766 & 0.209 & 1.000 & 1 \\
Spain & 1.061 & -0.230 & 0.298 & 0.079 & -0.537 & 1.000 & 1 \\
Sweden & 1.050 & -0.007 & 0.233 & 0.388 & 1.544 & 3.207 & 17 \\
Switzerland & 1.219 & 0.172 & 0.082 & 0.569 & -0.282 & 1.760 & 13 \\
United Kingdom & 1.128 & 0.016 & 0.557 & -0.820 & -0.125 & 1.000 & 1 \\
United States & 1.044 & 0.536 & 2.803 & -1.510 & 1.544 & 4.416 & 19 \\
\hline Average & 1.508 & 0.000 & 0.000 & 0.000 & 0.000 & 1.508 & \\
\hline & & & & & & & \\
\hline
\end{tabular}

Note: the fully corrected scores do not always add up to the indicated sum since for the cases were the result was below one we truncated it to the unity. 
Figure 1 - DEA and non-discretionary outputs

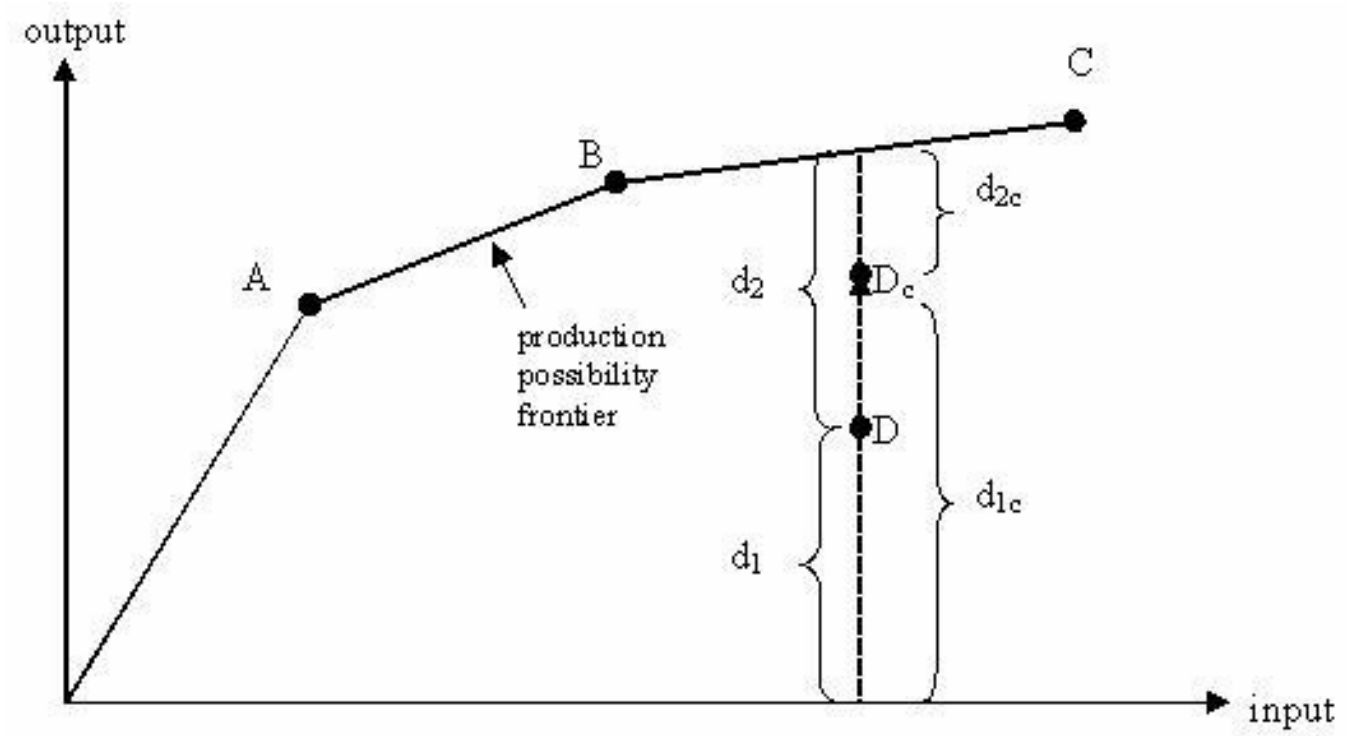

